\title{
Geochemistry of thermal waters of the Okhotsk Sea shore, Far East of Russia
}

\author{
Bragin I.V. ${ }^{1}$, Chelnokov G.A. ${ }^{1}$, Kharitonova N.A. ${ }^{1}$
}

${ }^{1}$ Far East Geological Institute FEB RAS, prospect 100-letiya Vladivostoka 159, 690022, Vladivostok, Russia bragin ivan@mail.ru

New data on hydrogeochemistry of thermal waters of the Okhotsk sea-shore (Ulskiy, Annensky Tumnin, Talaya, Paratunka, Dagi and Lesogorsky) is presented in the paper. Sikhote-Alin ridge thermal waters with crystalline host rocks refer to sulfate-hydrocarbonate or hydrocarbonate sodium fresh waters with elevated silicon content (up to $41 \mathrm{ppm}$ ), lowest TDS $(<0.3 \mathrm{~g} / \mathrm{L})$, alkaline $(9.1<\mathrm{pH}<9.3)$. Thermal waters of Talaya and Paratunka refer to sedimentary basins, resulting in presence of sulfate and chlorine in main ions, higher TDS $(1-1.2 \mathrm{~g} / \mathrm{L})$, lower $\mathrm{pH}(\sim 8.6)$ values and reducing conditions $(-82>\mathrm{Eh}>-157 \mathrm{mV})$. Geological conditions were proved by shapes of REE patterns (positive Eu-anomaly for sedimentary basins).

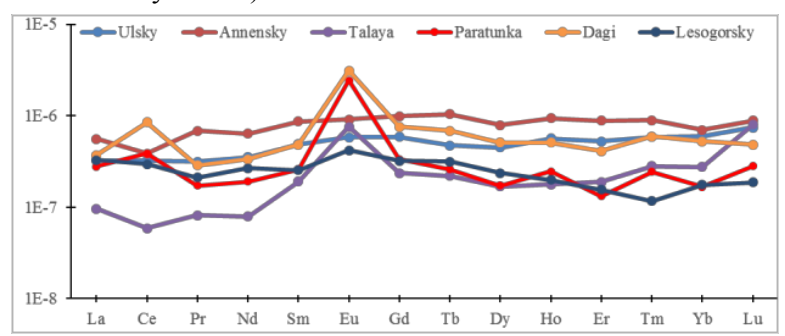

Stable water isotopes led us to divide roughly studied waters into two groups, using peculiarities of moisture source for water recharge areas. First group: Tumin, Annensky and Talaya with more "continental" climate as for mainland thermal waters, forming isotopically lighter water and second group: Ulskiy, Paratunka, Dagi and Lesogorsky, with "marine" climate of Sakhalin and Kamchatka, forming isotopically heavier water.

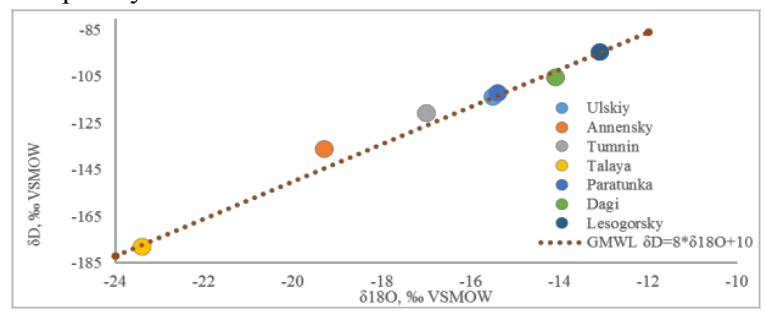

This study was made with support of Russian scientific foundation, grant \# 18-77-10007. 